cannot think of a single research question that could justify actively seeking exposing children to SHS or preventing parents from stopping smoking to provide a healthier environment for themselves and their families. Although each study requires and individual assessment of the risk-benefit ratio, as a general rule, experimental studies involving exposure to SHS should be discouraged, preferring observational designs built upon the premise that all efforts will be made to support smoking cessation and eliminate SHS.

Contributors All co-authors participated in the preparation of the manuscript.

Competing interests None.

Provenance and peer review Not commissioned; internally peer reviewed.
Tobacco Control 2012;21:383-384.

doi:10.1136/tobaccocontrol-2012-050466

\section{REFERENCES}

1. Montaldo L, Montaldo P, Caredda E, et al. Association between exposure to secondhand smoke and sleep bruxism in children: a randomised control study. Tob Control 2012;21:392-5.

2. Anon. World Medical Association. Declaration of Helsinki: ethical principles for medical research involving human subjects. JAMA 2000;284:3043-5.

\title{
Association between exposure to SHS and sleep bruxism in children: further details on the trial
}

Luisa Montaldo, ${ }^{1}$ Paolo Montaldo ${ }^{2}$

I am writing in response to the concerns raised about the randomised trial published by your journal and conducted by my team. ${ }^{1}$ This research was part of a larger project focusing on the education of families and children about the risks of smoking and SHS. At the beginning of the trial, parents were all informed about the risks of SHS and after the end of the trial, they were all involved in lessons held by a psychologist and a doctor. SHS is indeed a "...serious public health threat" and during the research, smoking and exposure to SHS have never been encouraged.

As stated, the trial included as many as 27 families who refused to participate.

'Department of Dentistry, Second University of Naples, Naples, Italy: ${ }^{2}$ Department of Pediatrics, Second University of Naples, Naples, Italy

Correspondence to Dr Luisa Montaldo, Department of Dentistry, Second University of Naples, via de crecchio, Naples, Italy; Imontaldo@libero.it
Most families refused to be included in the trial after being randomly selected either in group 1 or in group 2. Data about these 27 families were not reported and they were all listed among those refusing to participate. Some of these families were part of group 1 and decided not to participate because, in spite of being informed about the risks of SHS, they reported that they would not have been able to reduce SHS exposure for their children. Other families were part of group 2 and, aware of the risks of SHS, decided to reduce it and therefore did not participate. Those families were just excluded from the study and were not encouraged to continue smoking. All the parents of group 2 remaining in the trial were those who reported not being able to reduce children's exposure to SHS. Therefore, in group 1, the trial was interventional, but in group 2, it was just observational.

\section{What this paper adds}

- The purpose of this letter is to reply to the concerns raised about the randomised trial 'Association between exposure to secondhand smoke and sleep bruxism in children: a randomised control study'.

- In the trial, group 2 included those parents who reported not being able to reduce SHS children exposure. There was no action on this group.

- In group 1, the trial was interventional; in group 2, it was just observational.

I can understand that the above mentioned information is needed as it was not fully described in the paper and readers may misunderstand the instructions given during the trial. Under no circumstances should smoking be encouraged and every study should fulfil this requirement.

Tobacco Control 2012;21:384

doi:10.1136/tobaccocontrol-2012-050584

\section{REFERENCE}

1. Montaldo L, Montaldo P, Caredda E, et al. Association between exposure to secondhand smoke and sleep bruxism in children: a randomised control study. Tob Control 2012:21:392-5. 